магистрант кафедры общей экономики

Томского государственного университета

\section{ВЛИЯНИЕ СПЕЦИАЛЬНЫХ НАЛОГОВЫХ РЕЖИМОВ НА ДЕЯТЕЛЬНОСТЬ СУБЪЕКТОВ МАЛОГО И СРЕДНЕГО ПРЕДПРИНИМАТЕЛЬСТВА}

Аннотация:

В статье рассмотрена динамика развития малого и среднего предпринимательства в Российской Федерации (2010-2015 г2.). Определены налоговые льготы и преференции, предназначенные для стимулирования деятельности предприятий малого и среднего бизнеса. Проанализированы положительные и отрицательные стороны введения налоговых льгот, в том числе применения субъектами налогообложения специальных налоговых режимов. Предложены рекомендации по устранению выявленных недостатков, обозначены меры, нацеленные на повышение налоговых поступлений в бюджет и эффективное функционирование системы налогового контроля.

Ключевые слова:

малое и среднее предпринимательство, налогообложение, налоговые льготы, специальные налоговые режимы, налоговое стимулирование, налоговая политика, государственная поддержка.
Applicant for a Master's Degree, General Economics Department, Tomsk State University INFLUENCE OF SPECIAL SMALL AND MEDIUM-SIZED BUSINESSES

Summary:

The article deals with the dynamics of the development of small and medium-sized businesses in the Russian Federation (2010-2015). The research defines tax exemptions and preferences, meant for activity stimulation of small and medium-sized businesses. The paper analyzes advantages and disadvantages of introducing tax exemptions, including implementation of special tax regimes by the subjects of taxation. The author provides recommendations on elimination of the revealed disadvantages, identifies measures aimed at increasing tax revenues for the treasury and effective performance of the tax control system.

Keywords:

small and medium-sized businesses, taxation, tax exemptions, special tax regimes, tax incentive, tax policy, government support.

Стратегически важной задачей Правительства Российской Федерации является поддержка предпринимательства как фундаментальной группы налогоплательщиков. На примере развитых стран доказано, что чем больше в стране эффективно работающих и конкурентоспособных предприятий в промышленности, строительстве и сфере высоких технологий, тем весомее вклад этих предприятий в ВВП, вследствие чего обеспечивается рост экономического развития страны.

По информации Федеральной службы государственной статистики за 2015 г., число предприятий, зарегистрированных как юридические лица, было примерно равно 2,2 млн. Из этого количества лишь 19,3 тыс. - средние предприятия, оставшуюся часть представляют малые предприятия, из общего числа которых 90 \% составляют микропредприятия. Выручка от реализации товаров (работ, услуг) без учета НДС и акцизов от деятельности предприятий - юридических лиц составила 54,6 млрд р.

Что касается индивидуальных предпринимателей, то на 2015 г. их количество составляло 2,8 млн. Количество средних предприятий составило всего 432. 97 \% из общего числа малых предприятий - микропредприятия. Суммарный показатель выручки от деятельности малых и средних предприятий с учетом НДС, акцизов и других аналогичных обязательных платежей - 7,7 млрд р.

Рассматривая статистику за 2010 г., можно отметить, что предприятий - юридических лиц было значительно меньше - 1,7 млн, хотя в их число входило больше средних предприятий 25,1 тыс. В доле малых предприятий, как и сейчас, преобладали микропредприятия. Выручка от реализации товаров (работ, услуг) без НДС и акцизов была равна 26,35 млрд р., из них половина $(50,6 \%)$ - выручка малых предприятий.

В 2010 г. число индивидуальных предпринимателей составляло 2,9 млн - немногим больше, чем в 2015 г. Малые предприятия лидировали по количеству (2,885 млн), однако наибольший процент в общем объеме выручки составила выручка от микропредприятий (58,6 \%). Общая выручка составила 4,5 млрд р. с учетом НДС, акцизов и других обязательных платежей.

В целях стимулирования развития малого и среднего предпринимательства налоговым законодательством предусмотрен ряд льгот и преференций:

- специальные налоговые режимы, предусматривающие отмену уплаты части налогов, уплату налогов по сниженной ставке (упрощенная система налогообложения (УСН), единый 
налог на вмененный доход (ЕНВД), патентная система налогообложения (ПСН), единый сельскохозяйственный налог (ЕСХH), соглашение о разделе продукции);

- налоговые каникулы на два года для впервые зарегистрировавшихся индивидуальных предпринимателей, предоставляемые по ряду видов деятельности (каждый регион вправе самостоятельно определять виды деятельности с указанием кода ОКВЭД; деятельность должна осуществляться в сфере социальных услуг, науки или производства; ИП должен находиться на УСН или ПСН);

- патентная система для самозанятых граждан, предусматривающая упрощенный порядок ведения отчетности, уплаты налогов (в Томской области ПСН охвачены 47 видов деятельности, включая услуги проведения ремонта, парикмахерские, автотранспортные, образовательные услуги и некоторые другие);

- плательщики ЕНВД и ПСН не обязаны проводить наличный расчет с помощью контрольно-кассовых машин, им достаточно выдавать товарный чек, квитанцию или иной документ, подтверждающий прием денег;

- отсрочка или рассрочка выплат во внебюджетные фонды;

- упрощенное ведение бухгалтерского учета и др.

Анализируя показатели поступлений налогов от субъектов, находящихся на специальных налоговых режимах (по данным Федеральной налоговой службы), за 2015-2016 гг., можем сделать вывод: за исследуемый период УСН стала более привлекательной для налогоплательщиков (рис. 1). Возможно, этому способствует ее универсальность и отсутствие жестких условий «вхождения». Поступления по УСН увеличились в абсолютном соотношении на $13 \%$. Система ЕНВД востребована меньше за счет существования определенного ограничения по видам деятельности и особого механизма расчета. По результатам применения ECXH очевидна положительная динамика - увеличение поступлений на 54 \%. Предположим, что влияние на эту тенденцию оказали кризисные условия и политика импортозамещения. ПСН по-прежнему остается наименее популярным налоговым режимом, несмотря на простоту его использования.

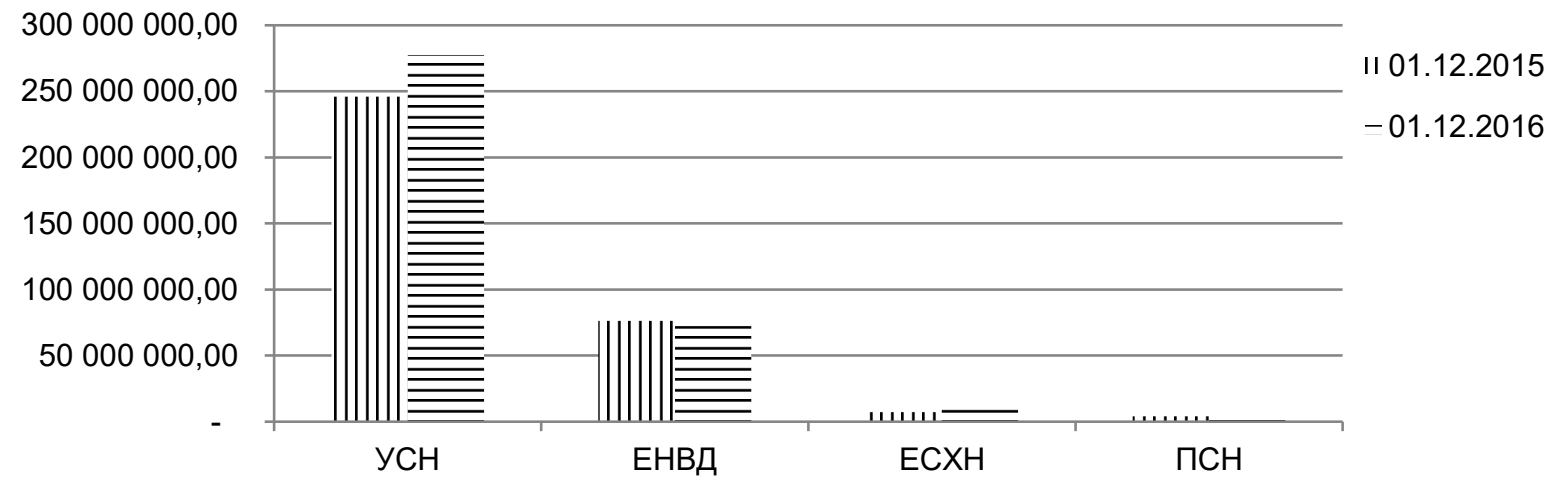

Рисунок 1 - Поступление налоговых платежей от субъектов, использующих специальные налоговые режимы, за 2015-2016 г., тыс. р.

В связи с возрастанием количества преференций, предоставляемых субъектам предпринимательства, у налоговых органов возникает все больше оснований для усиления налогового контроля за правомерностью их применения.

Существует опасение, что последние меры, проводимые государством в целях стимулирования деловой активности населения посредством смягчения налоговой политики, в действительности могут привести к ситуации, когда эти меры будут способствовать лишь увеличению нарушений налогового законодательства. К примеру, освобождение от уплаты НДС плательщиков специальных налоговых режимов УСН и ЕСХH привели к уплате налога с оборота по ставке 18 или 10 \% для микро- и малых предприятий производственной сферы, что ведет к повышению налоговой нагрузки и, как следствие, провоцирует предприятия к уходу «в тень» через фрирмыоднодневки [1, с. 48-49]. Кроме того, правительство обсуждает возможность повышения ставок НДС до 25 \%, что может усугубить сложившуюся ситуацию. В связи с этим целесообразно было бы ограничить круг субъектов, подпадающих под спецрежимы, сведя его до предприятий производственной, социальной, инновационной и других стратегически важных сфер экономики.

Как и прежде, основную финансовую нагрузку в деятельности предприятий представляют страховые взносы в социальные фонды. Правительством Российской Федерации рассматривается возможность снижения ставок до $20 \%$, что поспособствует выводу зарплат из тени.

В целях повышения налоговых поступлений в бюджет и эфрфективного функционирования системы налогового контроля необходимым представляется: 
- повышение финансовой грамотности предпринимателей и населения в целом, поскольку некоторые налоговые правонарушения происходят бессознательно, из-за недостаточной компетенции в том или ином вопросе;

- повышение дисциплины налогоплательщиков посредством ужесточения наказаний за налоговые правонарушения, в частности повышение штрафов [2];

- налаживание партнерских отношений налоговых органов и субъектов налогообложения путем консультаций, распространение системы налогового мониторинга на субъекты малого и среднего предпринимательства;

- более тщательное отслеживание эффективности предоставления льгот, повышение их адресности [3, с. 39].

При этом только комплексное и тщательно продуманное использование всех инструментов налоговой политики может привести к наиболее эффективным результатам как для государства, так и для самих налогоплательщиков.

\section{Ссылки:}

1. Тусеетулов А., Давлетшин Т., Салмина С. Анализ влияния спецрежимов на финансовые результаты малого бизнеса // Налоговый вестник. 2014. № 10. С. 44-50.

2. Coolidge J., Yilmaz F. Small business tax regimes // World Bank. Viewpoint. 2016. No. 349. February.

3. Герб А.А., Баландина А.С. Специфика налоговых льгот с позиции налогового администрирования и налогового контроля // Актуальные проблемы теории и практики налогообложения : сб. материалов IV Междунар. науч.-практ. конф. (Волгоград, 20 нояб. 2015 г.). Волгоград, 2015. С. 34-40.

\section{References:}

Coolidge, J \& Yilmaz, F 2016, 'Small business tax regimes', World Bank. Viewpoint, no. 349, February.

Gerb, AA \& Balandina, AS 2015, 'Specific features of tax benefits from the point of tax administration and tax control', Aktual'nyye problemy teorii i praktiki nalogooblozheniya: sb. materialov IV Mezhdunar. nauch.-prakt. konf. (Volgograd, 20 noyab. 2015 g.), Volgograd, pp. 34-40, (in Russian).

Tufetulov, A, Davletshin, T \& Salmina, S 2014, 'Analysis of the influence of special regimes on financial results of small business', Nalogovyy vestnik, no. 10, pp. 44-50, (in Russian). 